\title{
32. BOTTOM WATER CONDITIONS INDICATED BY SURFACE FEATURES OF DETRITAL SILICATE GRAINS AT SITE 276
}

\author{
A. Thomas Ovenshine, U.S. Geological Survey, Menlo Park, California \\ Stanley V. Margolis, Department of Oceanography at Hawaii Institute of Geophysics, \\ University of Hawaii, Honolulu, Hawaii \\ and \\ Richard R. Larson, U.S. Geological Survey, Washington, D.C.
}

\begin{abstract}
Many of the sand-sized silicate grains recovered during the abortive drilling at Site 276 are polished, iron stained, or coated with black or brown ferruginous material. Examination of eight representative grains with the scanning electron microscope and energy-dispersive X-ray analyzer shows that the ferruginous coatings are of two types: (1) black scale generally preferentially developed in grain surface depressions, and (2) smooth brown sheaths of hydrous(?) iron that completely envelope grains. The black scale typically contains major amounts of $\mathrm{Fe}$, minor $\mathrm{Si}$, and traces of $\mathrm{Al}, \mathrm{K}, \mathrm{Ca}, \mathrm{Ti}$, and $\mathrm{Mn}$. The polish exhibited by many quartz and feldspar grains results from development of a smooth coating of silica containing minor or trace Fe.

The coatings on the detrital silicate grains at Site 276 indicate that the western boundary current, which impinges on the site, is oxygenated, and silica rich. The results of the study show that iron staining, and the formation of siliceous and ferruginous coatings, can occur at oceanic depths $(4671 \mathrm{~m})$.
\end{abstract}

\section{INTRODUCTION}

The surficial layer of sediment at Site 276 (located near the southeast edge of the Campbell Plateau in water 4671 meters deep) consists of medium to coarse sand and possibly sandy gravel interpreted as a winnowed lag deposit formed through erosion of Tertiary deposits by a vigorous western boundary current (Site Report, Chapter 3, this volume). Many of the detrital silicate grains, in which quartz and feldspar predominate, are highly spherical, very well rounded, and exhibit brilliantly "polished" surfaces. Others are iron stained or coated by black or brown crusts. Eight grains, representative of the variety of types seen in the samples, have been studied by scanning electron microscope (SEM) and energy-dispersive analysis of Xrays. The purpose of this report is to present the micrographs and analytical information obtained.

\section{METHODS}

The micrographs were taken on a scanning electron microscope (ETEC Autoscan, Model U-1), operated at $20 \mathrm{kv}$. The elemental analyses were made in the SEM with an energy-dispersive X-ray system (EDAX International) having a resolution of $165 \mathrm{ev}$. The SEM preparation consisted of coating the mounted grains with carbon in a vacuum evaporator. Carbon was used as the conductive coating, rather than gold, to eliminate the absorption of the X-rays to be analyzed.

\section{RESULTS}

\section{Ferruginous Coatings}

Two types of ferruginous coatings are observed on silicate grains from Site 276. The most common form is a black or dark brown, rough-surfaced scale developed in irregular patches (Plate 1, Figures 1-4). The black coating occurs more commonly in depressions in the grain surface (Plate 1, Figure 2), is seldom found on corners or projections of grains (Plate 1, Figure 1), and ranges up to $0.5 \mathrm{~mm}$ in thickness. In many examples the scale can be broken off with a needle to reveal an underlying "polished" grain surface. High magnification photomicrographs of the scale suggest that it forms as very small irregular patches which coalesce as growth continues (Plate 1, Figures 3, 4). EDAX study indicates that the scale consists of major $\mathrm{Fe}$; major to minor $\mathrm{Si}$; and minor to trace amounts of $\mathrm{Al}, \mathrm{K}, \mathrm{Ca}, \mathrm{Ti}$, and $\mathrm{Mn}$. Very similar ferruginous coatings on eolian quartz grains have been illustrated by Krinsley and Margolis (1971, fig. 4, D and E).

The other type of ferruginous coating is a light brown or light red-brown patina that completely envelopes and somewhat subdues the primary surface of the original silicate grain. Under the binocular light microscope, coatings of this type are up to $0.5 \mathrm{~mm}$ in thickness and show subbotryoidal forms. One specimen studied under SEM (Plate 1, Figures 5, 6; Plate 2, Figure 1) shows a complex pattern of surface cracking probably caused by 
desssiccation of a coating composed of hydrous iron oxide. Beneath the surface patina is a rind of partially altered feldspar ("b" in Plate 2, Figure 1) above less altered feldspar ("c" in Plate 2, Figure 1).

\section{Silica Coatings}

Brilliant "polish" occurs on about half of the grains of quartz, feldspar, gneiss, and leucocratic plutonic rocks in the samples. The "polish" is most highly developed on rounded salients of the grain surface and on the parts of a grain having the smallest radius of curvature. Examination of "polished" surfaces using SEM generally shows an absence of abrasion or solution features; instead, the "polished" surfaces show relatively large smooth areas locally interrupted by very subdued "steps" that are either sublunate or irregular in plan view (Plate 2, Figures 2, 3). Analysis with EDAX indicates that the "polished" surfaces are major, $\mathrm{Si}$, locally with minor to trace amounts of Fe. The smooth, low-relief surfaces are interpreted as precipitated silica coatings (cf. Krinsley and Doornkamp, 1973, p. 67, fig. 76).

A high density of impact V's (Margolis and Kennett, 1971, p. 26-27 and pl. 4) occurs on one of the "polished" grains examined (Plate 2, Figures 4, 5, and 6). In this example, however, the episode of abrasion appears to predate the development of the discontinuous silica coating. This can be seen by Plate 2, Figure 6 where irregular patches of silica occur in the pits of some of the V's, and the smooth surface coating appears to be encroaching on one of the shallow impact marks.

\section{CONCLUSIONS}

Coatings on the oxides of iron and silica occur on many grains from Site 276. They probably form simultaneously: the coatings that are predominantly iron show minor to trace amounts of silica; and the coatings that are predominantly silica, show minor to trace amounts of iron. Smooth surface coatings of silica cause the "polish" developed on many of the grains. In one instance where evidence was available, the development of the silica layer appears to postdate the last abrasional episode to which the grain was subjected.

The presence of silica and iron coatings on detrital silicate grains indicates that the western boundary current that follows the southeast edge of the Campbell Plateau contains oxygenated, silica-rich waters that either transport, or have access to, a source of dissolved iron. The observations clearly show that the iron staining and coating of silicate grains is not confined to shallow marine or terrestrial environments.

\section{REFERENCES}

Krinsley, D. H. and Doornkamp, J. C., 1973. Atlas of quartz sand surface textures: London (Cambridge University Press).

Krinsley, D. H. and Margolis, S. V., 1971. Submicroscopic frosting on eolian and subaqueous quartz sand grains: Geol. Soc. Am. Bull., v. 82, p. 3395-3406.

Margolis, S. V. and Kennett, J. P., 1971. Cenozoic paleoglacial history of Antarctica recorded in subantarctic deep-sea cores: Am. J. Sci., v. 271, p. 1-36. 


\section{PLATE 1}

SEM photomicrographs of sand grains from Site 276.

Figure 1 Angular amber-colored quartz grain with ferruginous coating on lower half.

Figure 2 Rounded quartz grain with patch of ferruginous coating in a surface depression; coating is principally $\mathrm{Si}$ and $\mathrm{Fe}$ with minor $\mathrm{Mn}$ and trace $\mathrm{Ca}$ and Ti.

Figure 3 Patches of ferruginous coating locally coalesced and showing smooth surface. Coating shows major $\mathrm{Si}$ and $\mathrm{Ca}$ with minor $\mathrm{Al}, \mathrm{P}, \mathrm{K}, \mathrm{Fe}$, and traces of Ti.

Figure 4 Detail of a coating patch similar to those shown in Figure 3. Coating is major $\mathrm{Si}$ and $\mathrm{Fe}$, with minor $\mathrm{Al}$, and traces of $\mathrm{K}, \mathrm{Ca}$, and $\mathrm{Ti}$.

Figure $5 \quad$ Ferruginous coating on feldspar grain. Cracks presumably result from desiccation.

Figure 6 Detail of cracks from center of grain shown in Figure 5.

(See p. 1068)

\section{PLATE 2}

SEM photomicrographs of sand grains from Site 276.

Figure 1 Fragment of grain shown in Plate 1, Figures 5, 6. Area (a) is major $\mathrm{Fe}$, with minor $\mathrm{Si}$, and traces of $\mathrm{Al}, \mathrm{S}, \mathrm{K}, \mathrm{Ca}, \mathrm{Ti}$, and $\mathrm{Mn}$; area (b) is alteration rind(?) on feldspar composed of $\mathrm{Fe}$ and $\mathrm{Si}$, with minor $\mathrm{Al}, \mathrm{Ti}$, traces of $\mathrm{Mg}, \mathrm{P}, \mathrm{K}, \mathrm{Ca}$, and $\mathrm{Mn}$; area (c) is "fresh" feldspar with major $\mathrm{Si}$ and $\mathrm{Al}$ and minor $\mathrm{Na}, \mathrm{Ca}$.

Figure 2 Smooth coating on clear rutilated quartz grain with high polish; composition mainly $\mathrm{Si}$, locally with traces of $\mathrm{Fe}$ and $\mathrm{Ti}$.

Figure 3 Detail of smooth $\mathrm{Si}$ coating on grain shown in Figure 2; composition of adhering particles unknown.

Figure 4 Smoothly rounded quartz grain. Note linear abrasion feature extending from left edge toward center of grain.

Figure $5 \quad$ Impact V's on grain shown in Figure 4.

Figure 6 Impact V's with coating in "sheltered" areas; coating is major $\mathrm{Si}$, with minor $\mathrm{Fe}$.

(See p. 1069) 
PLATE 1
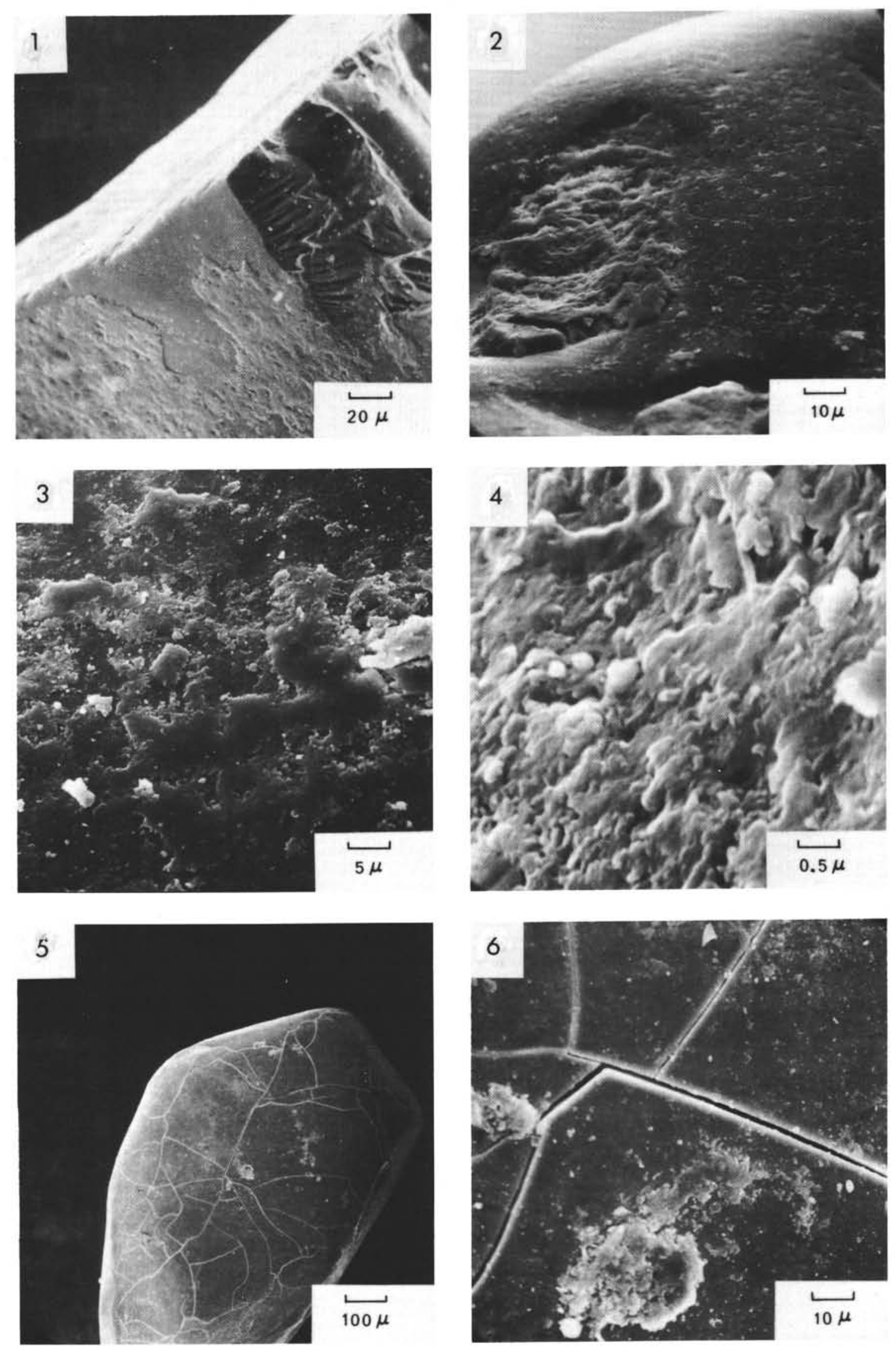
PLATE 2
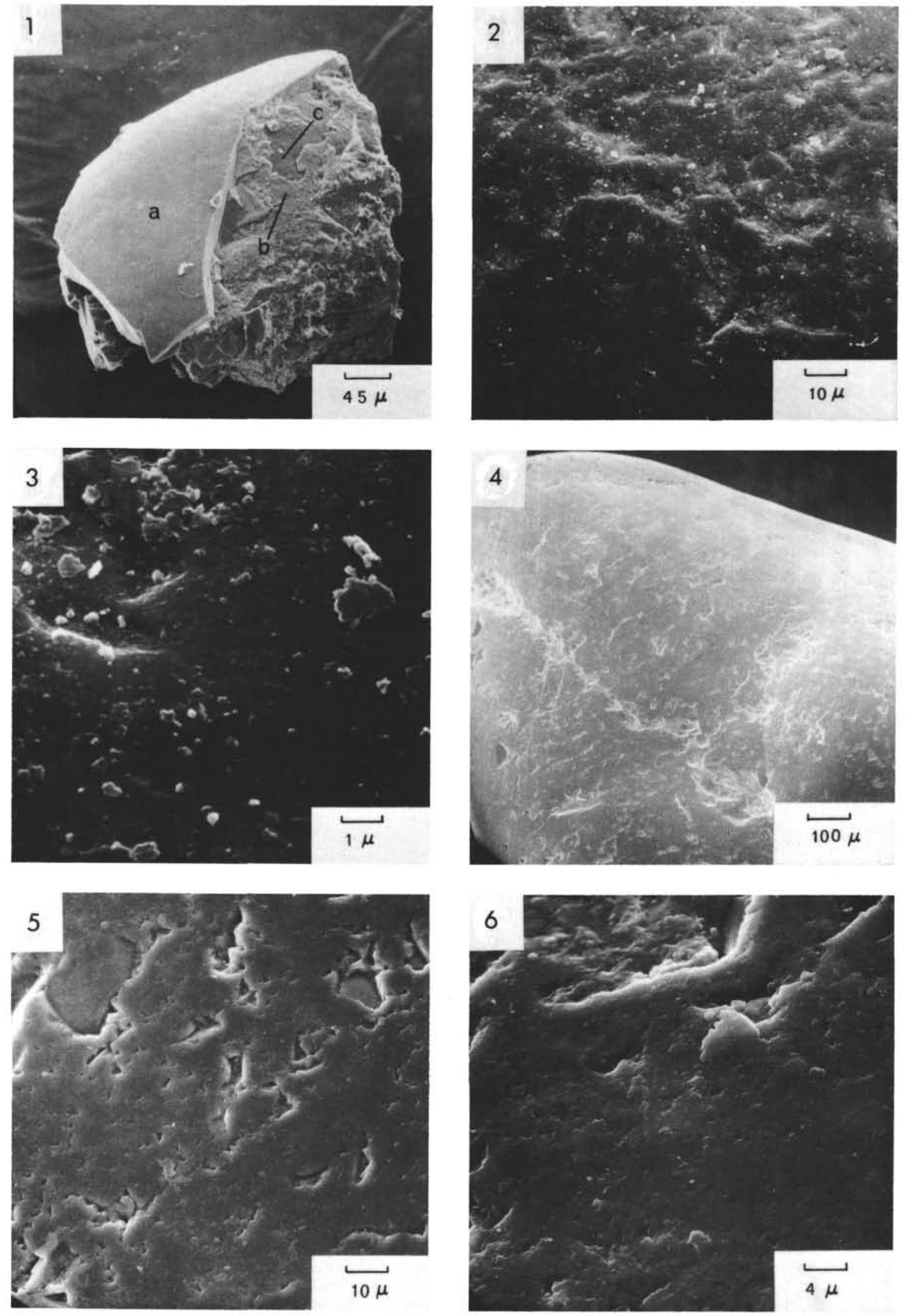